\title{
Management of autoimmune disease during the COVID-19 pandemic
}

\author{
Philip C Robinson \\ Associate professor ${ }^{1}$ \\ Senior staff specialist ${ }^{2}$ \\ Evan C Bursle \\ Senior lecturer' \\ Infectious diseases \\ physician $^{3}$ \\ Clinical microbiologist 3,4 \\ 1 Faculty of Medicine, \\ University of Queensland, \\ Herston, Queensland \\ ${ }^{2}$ Royal Brisbane \& Women's \\ Hospital, Metro North \\ Hospital \& Health Service, \\ Brisbane \\ ${ }^{3}$ Infection Management \\ Services, Princess \\ Alexandra Hospital, Metro \\ South Hospital and Health \\ Service, Brisbane \\ ${ }^{4}$ Sullivan Nicolaides \\ Pathology, Bowen Hills, \\ Queensland
}

\section{Keywords}

coronavirus, corticosteroids,

COVID-19, disease-

modifying antirheumatic drugs, DMARDs

Aust Prescr 2020;43:146-7 https://doi.org/10.18773/ austprescr.2020.058

First published

18 August 2020
Immunosuppression is an important part of the management of autoimmune diseases. As with all treatments, immunosuppressants are prescribed based on a balance of harm and benefit. This balance needs to be re-evaluated in the context of the pandemic caused by severe acute respiratory syndrome coronavirus-2 (SARS-CoV-2). However, as the pandemic is rapidly evolving, this evaluation must be made with constantly changing, imperfect information. The evaluation must also consider each person's risk of exposure and infection, public health measures and a range of risk factors.

When coronavirus disease (COVID-19) emerged, there was concern regarding the potential for poor outcomes in patients taking immunosuppressive drugs for rheumatic diseases. As the pandemic has evolved, reports have added to our understanding of the outcomes for patients who are already taking immunosuppressant drugs. However, these studies have limitations which need to be considered when making recommendations based on this information. In discussions about COVID-19 with patients taking immunosuppressants, the first consideration is their risk of being infected. This depends on local epidemiological factors such as the numbers of active cases and the level of community transmission. For example, the risk of infection will be much higher for a patient living in a community with high levels of transmission compared to a patient working exclusively at home in an area with a low prevalence. These risks will vary throughout the pandemic, influenced by public health measures such as case finding and isolation, physical distancing and hand hygiene.

If a patient is infected, the risk of an adverse outcome depends on modifiable and non-modifiable factors. Non-modifiable risk factors include older age and comorbidities. Initial data from 600 patients with rheumatic diseases who were infected do not show any difference in the risk of hospitalisation for COVID-19 between patients with rheumatoid arthritis, and patients with systemic lupus erythematosus, psoriatic arthritis, axial spondyloarthritis or vasculitis. Another series of 86 patients from New York found no increase in hospitalisation for patients with rheumatic disease compared to the background rate in the community. The mortality rate was $1 \%$, which was consistent with general cohorts of COVID-19 patients. ${ }^{2}$
Modifiable risk factors for adverse outcomes in COVID-19 include drugs. So far there has not been any increase in the risk of hospitalisation for COVID-19 in rheumatic disease patients taking disease-modifying antirheumatic drugs alone (e.g. methotrexate) or in combination with biologics or Janus kinase inhibitors, compared to patients who were not taking these drugs. ' Similarly, non-steroidal anti-inflammatory drugs and hydroxychloroquine did not alter the risk of hospitalisation with COVID-19. Treatment with tumour necrosis factor inhibitors reduced the odds of hospitalisation, with an adjusted odds ratio (aOR) of 0.4 (95\% confidence interval $(\mathrm{Cl})$ 0.19-0.81). However, prednisone at a dose of $10 \mathrm{mg}$ or more increased the odds of hospitalisation - aOR 2.05 (95\% Cl 1.06-3.96). ' Another study of people infected with COVID-19 compared 52 patients with rheumatic disease, including 39 taking immunosuppressants, with 104 matched COVID-19 positive controls. There was no significant difference between the groups in hospitalisation, length of stay in hospital, oxygen therapy or death. However, patients with rheumatic disease were more likely to require intensive care or ventilation. ${ }^{3}$

In a series of 525 patients with inflammatory bowel disease, poorer outcomes with COVID-19 were associated with increasing age, comorbidities and systemic glucocorticoids. Tumour necrosis factor inhibitors were not associated with an increased risk of a poor outcome. Aminosalicylates, such as sulfasalazine, were associated with some composite end points of poor outcome but not others, so caution is required when interpreting this result and further study is required. ${ }^{4}$

When advising patients taking immunosuppressive drugs during the pandemic, a comprehensive risk assessment should consider the consequences of changing treatment. Stopping the drugs could cause a flare of the underlying disease or other disease complications.

As with all treatment decisions, patients have their own values and tolerances for risk. Patients are often substantially influenced by personal, financial and social factors. General guidance is often helpful, with subsequent adjustments to suit the patient's own situation. The American College of Rheumatology (ACR) and the European League Against Rheumatism recommend that in the absence 
of confirmed or suspected COVID-19, treatment for rheumatic disease should not be altered. ., $^{5}$ If SARS-CoV-2 infection is confirmed, ACR guidelines suggest suspending immunosuppression, however they do state that as part of a shared decision-making process interleukin- 6 inhibitors may be continued. The potential to continue therapy may be extended to other immunosuppressants in later versions of the guidelines.

As we learn more about immunosuppressed patients and their response to COVID-19 our approach will undoubtably be refined. For now, we need to recognise that there is no right answer - the limited information we have must be tailored to each patient.

\section{REFERENCES}

1. Gianfrancesco M, Hyrich KL, Al-Adely S, Carmona L, Danila MI, Gossec L, et al.; COVID-19 Global Rheumatology Alliance. Characteristics associated with hospitalisation for COVID-19 in people with rheumatic disease: data from the COVID-19 Global Rheumatology Alliance physician-reported registry. Ann Rheum Dis 2020;79:859-66. https://doi.org/ 10.1136/annrheumdis-2020-217871

2. Haberman R, Axelrad J, Chen A, Castillo R, Yan D, Izmirly P, et al. Covid-19 in immune-mediated inflammatory diseases case series from New York. N Engl J Med 2020;383:85-8. https://doi.org/10.1056/NEJMc2009567

3. D'Silva KM, Serling-Boyd N, Wallwork R, Hsu T, Fu X, Gravallese EM, et al. Clinical characteristics and outcomes of patients with coronavirus disease 2019 (COVID-19) and rheumatic disease: a comparative cohort study from a US 'hot spot'. Ann Rheum Dis. Epub 2020 May 26. https://doi.org/10.1136/annrheumdis-2020-217888

4. Brenner EJ, Ungaro RC, Gearry RB, Kaplan GG, Kissous-Hunt M, Lewis JD, et al. Corticosteroids, but not TNF antagonists, are associated with adverse COVID-19 outcomes in patients with inflammatory bowel diseases: results from an international registry. Gastroenterol. In press, uncorrected proof, 2020 May 18. https://doi.org/10.1053/ j.gastro.2020.05.032

\section{FURTHER READING}

National COVID-19 Clinical Evidence Taskforce. Caring for people with COVID-19. Living guidelines. 2020.

https://covid19evidence.net.au [cited 2020 Aug 6]
Philip Robinson reports personal fees from Abbvie Eli Lilly, Gilead, Janssen, Novartis, UCB Pharma, Roche, Pfizer, and non-financial support from Roche and BMS, and research grant funding from Janssen, UCB Pharma and Novartis. He is the chair of the COVID-19 Global Rheumatology Alliance steering committee which has funding from Amgen and Janssen.

Evan Bursle has received speaker fees from Gilead, Novartis and Pfizer.

5. Mikuls TR, Johnson SR, Fraenkel L, Arasaratnam RJ, Baden LR, Bermas BL, et al. American College of Rheumatology guidance for the management of rheumatic disease in adult patients during the COVID-19 pandemic: Version 1. Arthritis Rheumatol 2020;72:1241-51. https://doi.org/10.1002/art.41301

6. Landewé RB, Machado PM, Kroon F, Bijlsma HW Burmester GR, Carmona L, et al. EULAR provisional recommendations for the management of rheumatic and musculoskeletal diseases in the context of SARS-CoV-2. Ann Rheum Dis 2020;79:851-8. https://doi.org/10.1136/ annrheumdis-2020-217877 